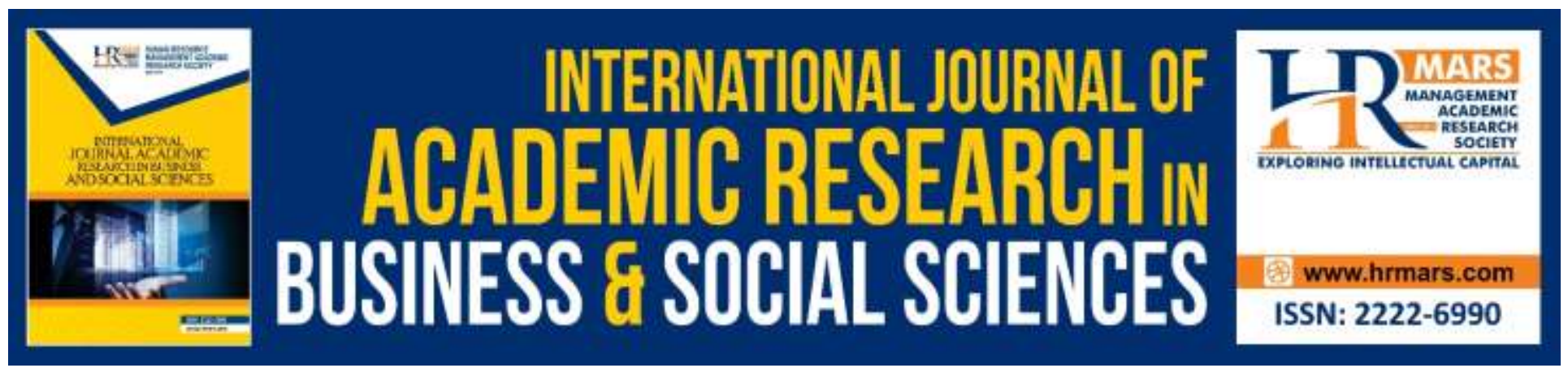

\title{
Current Trends in the Integration of Case-Based Reasoning and Semantic Web
}

\section{Shahnita Shaharin, Aslina Saad, Mashitoh Hashim, Nor Hasbiah Ubaidullah}

To Link this Article: http://dx.doi.org/10.6007/IJARBSS/v9-i14/6518

DOI: 10.6007/IJARBSS/v9-i14/6518

Received: 22 June 2019, Revised: 17 July 2019, Accepted: 02 August 2019

Published Online: 22 September 2019

In-Text Citation: (Shaharin, Saad, Hashim, \& Ubaidullah, 2019)

To Cite this Article: Shaharin, S., Saad, A., Hashim, M., \& Ubaidullah, N. H. (2019). Current Trends in the Integration of Case-Based Reasoning and Semantic Web. International Journal of Academic Research in Business and Social Sciences, 9(14), 107-120.

Copyright: (c) 2019 The Author(s)

Published by Human Resource Management Academic Research Society (www.hrmars.com)

This article is published under the Creative Commons Attribution (CC BY 4.0) license. Anyone may reproduce, distribute, translate and create derivative works of this article (for both commercial and non-commercial purposes), subject to full attribution to the original publication and authors. The full terms of this license may be seen

at: http://creativecommons.org/licences/by/4.0/legalcode

Vol. 9, No. 14, Special Issue: Education 4.0: Future Learning, Pg. 107 - 120

http://hrmars.com/index.php/pages/detail/IJARBSS

JOURNAL HOMEPAGE

Full Terms \& Conditions of access and use can be found at http://hrmars.com/index.php/pages/detail/publication-ethics 


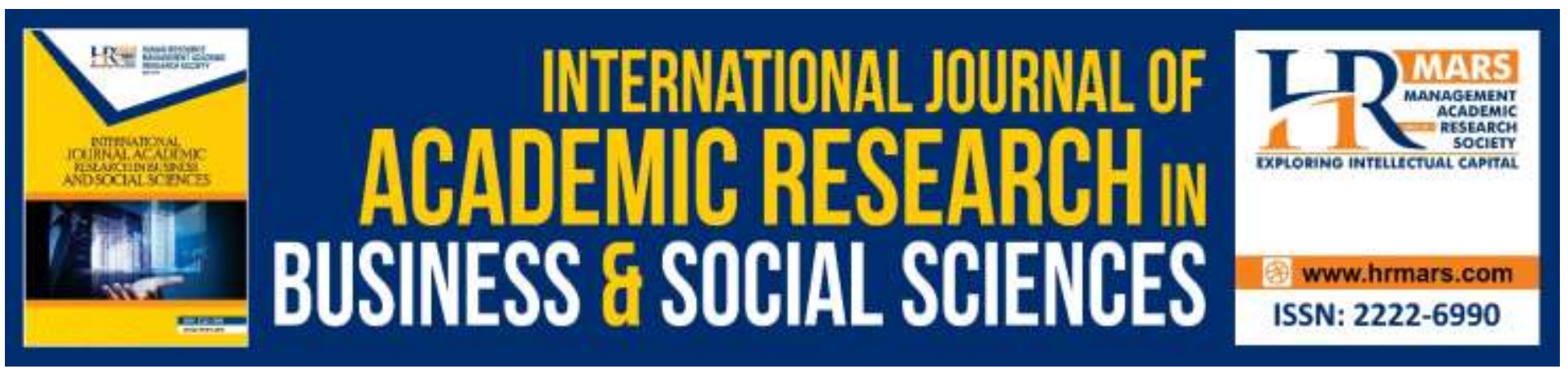

\title{
Current Trends in the Integration of Case-Based Reasoning and Semantic Web
}

\section{Shahnita Shaharin, Aslina Saad, Mashitoh Hashim, Nor Hasbiah Ubaidullah}

Department of Computing, Faculty of Art, Computing, and Creative Industry, Sultan Idris Education University, 35900 Tanjung Malim, Perak, Malaysia

Email: shahnita79@gmail.com, aslina@fskik.upsi.edu.my,mashitoh.hashim@fskik.upsi.edu.my hasbiah@fskik.upsi.edu.my

\begin{abstract}
Case-Based Reasoning (CBR) and semantic web are intelligent methods or techniques that have been used in number of critical fields. Both methods have unique strengths and immense potential in problem solving in a wide range of domains. The main aim of this paper is to highlight an overview of the current efforts by researchers to integrate the capabilities of both techniques of CBR and semantic web. Through an analysis on the current literature involving 21 related articles, a taxonomy was developed indicating there were three stands of research focus. First, $38 \%(n=8)$ of the articles involved studies of new methods that combined both techniques. Second, 33.3\% $(n=7)$ of the articles dealt with the development of working frameworks or new approaches. Third, $28.6 \%(n=6)$ of the articles focused on efforts to develop systems that integrated both techniques. In particular, the analysis showed that the medical field was the dominant field in which the integrated technique was widely used in solving medical-related problems. In light of this emerging potential, both techniques can also be applied to help provide efficient and effective problem-solving solutions for other important fields.
\end{abstract}

Keywords: Case-Based Reasoning, Semantic Web, Ontology

\section{Introduction}

Of late, Case-Based Reasoning (CBR) technique, which is an important approach in the field of artificial intelligence, is becoming prominent in many recent studies by researchers. The basic concept of the CBR technique centers on the application of the current problem-solving approach by making comparison with previously solved problems. Essentially, this technique assumes that if two problems being compared are identical, then the same technique used in solving a particular problem can be applied accordingly to solve other problem (Kolodner, 2014; Bergmann et al., 2005). CBR technique consists of four phases, namely retrieve, reuse, revise and retain phases (Aamodt \& Plaza, 1994). 
INTERNATIONAL JOURNAL OF ACADEMIC RESEARCH IN BUSINESS AND SOCIAL SCIENCES

Vol. 9, No. 14, Special Issue: Education 4.0: Future Learning. 2019, E-ISSN: 2222-6990 @ 2019 HRMARS

Firstly, the retrieve is a process where one or more problems that have the same values with the current problem are fetched or retrieved from the case database. Adaptation process is performed to make the necessary adjustments by taking into account the characteristics of the current problems. Secondly, in the reuse phase, the selected solutions of previous cases are used to solve the current problem. Thirdly, for the revise phase, the solution of the current problem is tested and compared with the actual solution. Finally, in the retain phase, after successfully testing the chosen solution, paired-problems and paired-solutions are stored in the case database accordingly. The accumulated solutions on the database are reused to solve future problems as necessary. The main advantage of CBR technique lies in its ability to solve problems based on the experiences gained from previous encounters that led to proven effective solutions.

Meanwhile, Web 3.0, which is also known as semantic web, is based on the evolution of the web to its current state that connects information online. According to its founders (Berners-Lee et al., 2001), semantic web is an extension of existing web technology where information is defined and given meaning to enable collaboration between the man and the computer. The main aim of semantic web is not only confined to online access of information, but it involves an approach by which data on the web are assigned with clear meanings and linked to other information to enable the computer or the machine to manipulate such information for the purpose of automation, integration, reuse, or display of that information. In this regard, ontology is the main component of semantic web that defines information of the domain that it represents. Through such developed ontology, accessing information from multiple sources can be performed effectively. Ahmed, Khalid, Ammar, \& Shah, (2017); Ahmed, Majid, \& Zin, (2016)

A variety of knowledge-based systems have been developed to help people in the decision making process. Two important components in the knowledge-based system is the knowledge representation and reasoning mechanisms used in determining the selection of the appropriate solution. There are various methods of knowledge representation that can be applied in the development of a knowledge -based system such as frame, logic descriptions, object, hierarchies, graphs and ontologies based representation. The strength of the semantic web technique is the ontology component that able to represent complex knowledge in a more flexible, easy and meaningful way where each concept has a relationship with each other. Application of this technique is suitable because the knowledge acquision process is a very difficult and tedious process. This is even more so if it involves critical areas such as medical, security and engineering. The advantage of CBR technique is the reasoning mechanism that attempts to solve a problem by experience by making comparisons with past cases that have been solved. The current problem will be compared with the previous case by comparing the similarity value for each solution that are stored in the case database. The solution for each case is stored in the form of problem description and its paired solutions. By combining semantic web knowledge representation technique with CBR enable us to develop a more efficient and effective knowledge-based system. This is because the problem that is stored in the case base can be developed more easily and flexible by applying the ontology representation. In addition, the reasoning process for selecting the appropriate solutions can be done quickly and accurately from the semantic similarity matrixes procedure implemented. 
INTERNATIONAL JOURNAL OF ACADEMIC RESEARCH IN BUSINESS AND SOCIAL SCIENCES

Vol. 9, No. 14, Special Issue: Education 4.0: Future Learning. 2019, E-ISSN: 2222-6990 @ 2019 HRMARS

Research on the integration of both techniques based on ontology in a particular domain has been carried out successfully. Against this backdrop, this paper provides an in-depth discussion of current efforts by researchers to integrate the techniques of CBR and semantic web. Through a critical review of related literature involving several hundred contemporary articles, a taxonomy to help classify studies of the integration of both techniques more systematically was developed by the researchers.

\section{Methodology}

The research method of this study was based on a critical review of related literature comprising several hundred articles published from 2011 to 2015 that discussed the integration of CBR and semantic web techniques. Specifically, the survey only focused on articles that were written in English.

\section{Information Sources}

The information sources used in this study involved four (4) digital databases: (a) ACM, (b) Science Direct (for science, technical, and medical research papers), (c) IEEE Xplore, and (d) Web Of Science (for multi-discipline research papers involving science, arts, and humanities). The selection of these databases was based on their technical relevancy that highlights the overall description of the research area involving CBR and semantic web.

\section{Selection of Studies}

The selection of studies involved a number of processes, such as the search of information sources based on specific keywords that were related to the study being pursued. Such information that had been collected were combined to produce a list of all articles that were deemed relevant. Later, these articles were subjected to two phases of examination and filtering process. In the first phase, information of the articles was examined and filtered based on the articles' titles and abstracts to select relevant research articles. Replicated articles and articles that did not meet the selection criteria were discarded from the list of shortlisted articles. Subsequently, in the second phase of this process, the selected articles were reviewed, tested for their integrity (through detailed reading of the main texts), and finally filtered according to the same selection criteria.

\section{The Search}

The process of searching information sources was performed by using the "search box" of the four chosen databases. Keywords that were used were "case-based reasoning AND semantic web", which were specific to the study being undertaken. The scope of the search for articles was limited to the latest publication of studies spanning five years, which was from 2011 to 2015, to highlight the latest development in research involving the integration of both techniques. Furthermore, the scope of search was also limited to searching peer-reviewed journal articles and conference proceedings given their high degree of scientific and technical quality. Such sources of information were highly reliable given the rigorous review process by experts prior to their acceptance to appear in such journals or proceedings. Figure 1 shows the result of the process of searching such information. 
INTERNATIONAL JOURNAL OF ACADEMIC RESEARCH IN BUSINESS AND SOCIAL SCIENCES

Vol. 9, No. 14, Special Issue: Education 4.0: Future Learning. 2019, E-ISSN: 2222-6990 @ 2019 HRMARS

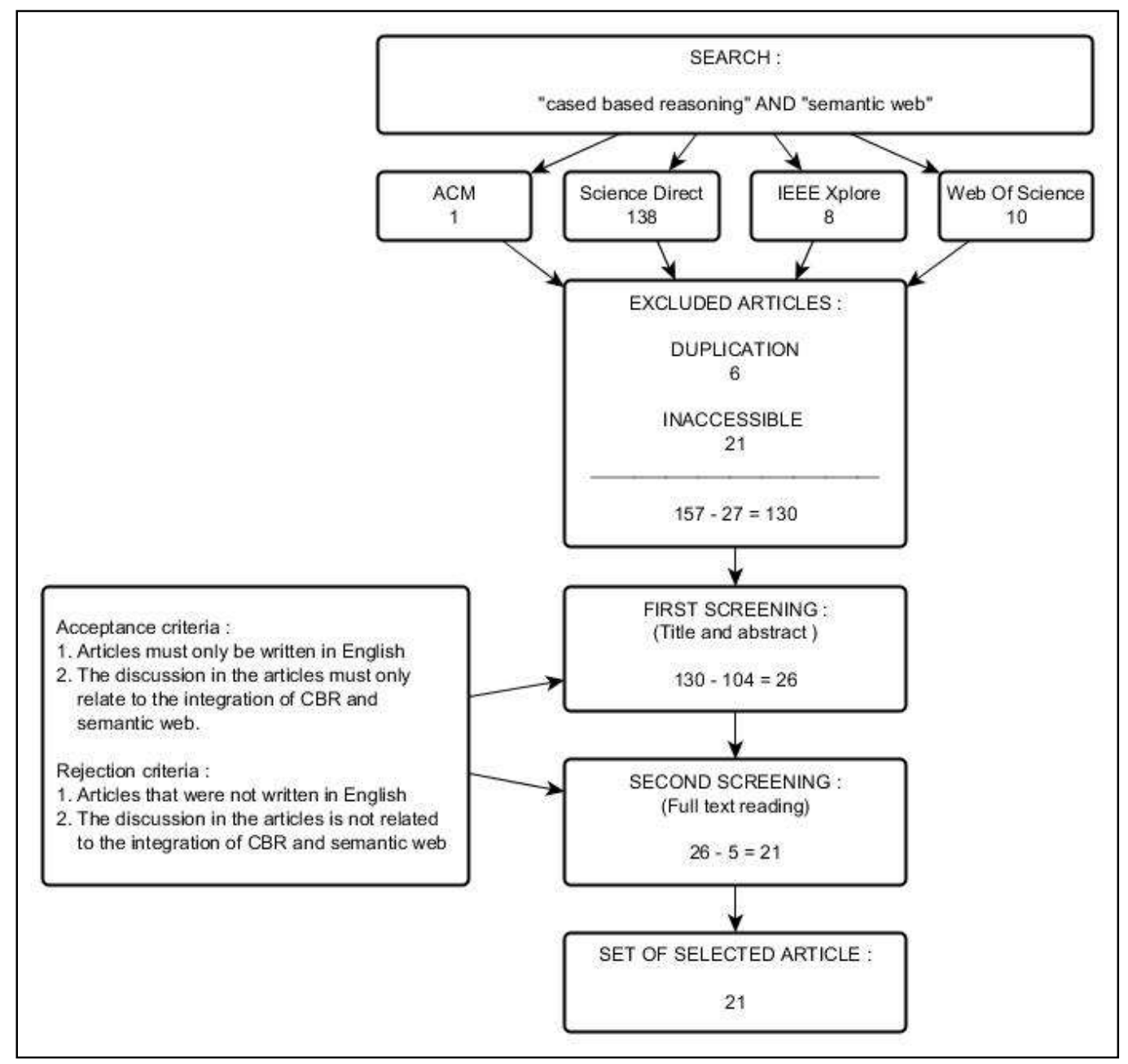

Figure 1. The flow chart of the selection process

The selection of articles for the survey research was based on two criteria, namely "acceptance" and "rejection" as illustrated in Figure 1. After casting aside duplicated articles from the information sources, the examining and filtering process of articles was performed in cycles based on the above criteria (i.e., acceptance and rejection). The acceptance criterion, which had been determined, was as follows: (a) articles must only be written in English, and (b) the discussion in the articles must only relate to the integration of CBR and semantic web. Whereas, the rejection criterion was as follows: (a) articles that were not written in English, and (b) the discussion in the articles is not related to the integration of CBR and semantic web. After the completion of the above process, each article was classified according to appropriate categories to develop a taxonomy for the field being studied, which would highlight the overall description of the current efforts and studies involving the integration of CBR and semantic web. 
INTERNATIONAL JOURNAL OF ACADEMIC RESEARCH IN BUSINESS AND SOCIAL SCIENCES

Vol. 9, No. 14, Special Issue: Education 4.0: Future Learning. 2019, E-ISSN: 2222-6990 @ 2019 HRMARS

\section{Selection Criteria}

The selection of articles for the survey research was based on two criteria, namely "acceptance" and "rejection" as illustrated in Figure 1. After casting aside duplicated articles from the information sources, the examining and filtering process of articles was performed in cycles based on the above criteria (i.e., acceptance and rejection). The acceptance criterion, which had been determined, was as follows: (a) articles must only be written in English, and (b) the discussion in the articles must only relate to the integration of CBR and semantic web. Whereas, the rejection criterion was as follows: (a) articles that were not written in English, and (b) the discussion in the articles is not related to the integration of CBR and semantic web. After the completion of the above process, each article was classified according to appropriate categories to develop a taxonomy for the field being studied, which would highlight the overall description of the current efforts and studies involving the integration of CBR and semantic web.

\section{Data Collection Process}

In the data collection process, information pertaining to the selected articles was organized into a table using the Microsoft Excel application. Articles were classified into appropriate categories to facilitate the process of organizing studies based on specific themes. Figure 1 depicts the flow chart of the selection process carried out in this study.

\section{Results}

The process of selecting articles on the four selected databases (i.e., ACM, Science Direct, IEEE Xplore, and Web of Science) yielded a total of 157 articles. A majority of the articles, totalling 138, were obtained from Science Direct database. Trailing far behind were articles from the Web of Science and IEEE Xplore databases, numbering 10 and eight (8) articles, respectively. Surprisingly, only one (1) article was selected from the ACM database. In addition, there were six (6) duplicated articles appearing in several different databases, and 21 articles that were not accessible as they would incur subscription fees. Thus, these articles were not considered in the selection process. Thus, in total, 130 articles were shortlisted in the first phase of the selection process.

The first phase of the filtering process, which was based on the criteria of titles and abstracts of the articles, drastically reduced the above number to only 26 articles, as 104 articles had not met such criteria. The former articles, in fact, were articles that had discussion regarding the integration of CBR and semantic web. Later, the second phase involved detailed reading of the articles, which subsequently identified five (5) articles were not relevant, and thus they were removed from the set of selected articles. Finally, only 21 articles were selected after having met all the selection criteria as depicted in Figure 1. These articles would then be subjected to further analysis to acquire a complete description of studies that have been carried out in this field. The final set of selected articles were then subjected to contents analysis of the manuscripts by thorough reading to help classify the articles into appropriate categories. 
INTERNATIONAL JOURNAL OF ACADEMIC RESEARCH IN BUSINESS AND SOCIAL SCIENCES Vol. 9, No. 14, Special Issue: Education 4.0: Future Learning. 2019, E-ISSN: 2222-6990 @ 2019 HRMARS

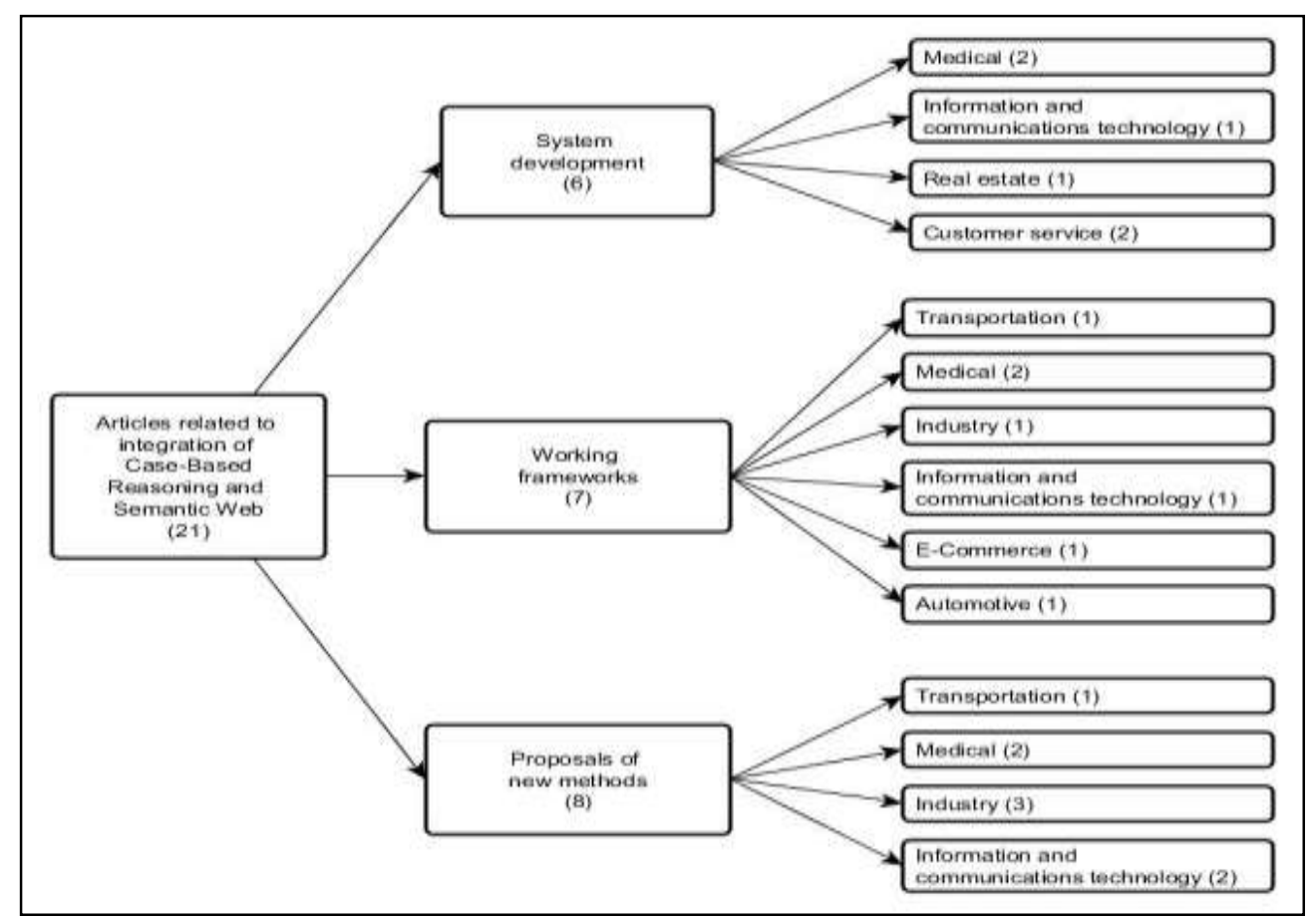

Figure 2. The taxonomy of the integration of CBR and semantic web based on literature review.

Essentially, by going through the discussion threads, three types of discourse were identified that focussed on the following themes: (a) system development, (b) working frameworks, and (c) proposals of new methods of integration of CBR and semantic web techniques. The final analysis revealed that eight (38\%) articles discussed new methods of applications that were based on the integration of the two techniques. From the total article under this category, $25 \%(2 / 8)$ of the article involves the medical field and $12.5 \%(1 / 8)$ articles respectively from the field of transportation, industrial, information and communication technologies, e-commerce and automotive. Not far behind, seven articles (33.3\%) focussed on the discussion pertaining to the development of working frameworks or new approaches for the integration of CBR and semantic web. For this category, out of 7 articles that have been classified $43.8 \%$ (3/7) of articles are from the industry, $28.6 \%(2 / 7)$ article each are from medicine and information technology and communications and $14.3 \%(1 / 7)$ article of the transport sector. Trailing closely, six (28.6\%) articles elaborated efforts in developing systems that combined both techniques. A total of $33.3 \%(2 / 6)$ of article each from the medical field and customer service, while $16.67 \%(1 / 6)$ of articles from the information and communication technologies and the property field out of the entire 6 articles in this category. Figure 2 summarizes the above findings.

\section{System Development}

Several efforts have been carried out in developing systems that integrate the techniques of CBR and semantic web. The integration of both techniques would help improve the method of accessing data, which are represented in the form of case representation using an ontology that is developed for a specific domain. More specifically, personalized access would be feasible as the search process is based on the criteria that are determined by the user based on a developed ontology. As a result, 
INTERNATIONAL JOURNAL OF ACADEMIC RESEARCH IN BUSINESS AND SOCIAL SCIENCES

Vol. 9, No. 14, Special Issue: Education 4.0: Future Learning. 2019, E-ISSN: 2222-6990 @ 2019 HRMARS

based on the accessed information, decisions to solve problems would be able to be executed accurately and promptly. Several successful personalized access systems have been deployed in a wide range of fields, which include diagnosis of patients in the medical domain (El-Sappagh et al., 2015; d'Aquin et al., 2013), customers service (Amailef \& Lu, 2013; Lee et al., 2015), real estate (Yuan et al., 2013), and information and communication technology (Flores et al., 2015).

\section{Proposed Working Framework}

Efforts to develop new working frameworks involving the integration of CBR and semantic web were also reviewed and analysed in this study. To date, several efforts have been undertaken in a number of important fields, such as medicine (Douali et al., 2011; Sanchez et al., 2014), automotive industry (Minhas et al., 2012), e-commerce (Chang et al., 2016), information and communication technology (Recio-García et al., 2014), industrial management (Pal \& Karakostas, 2014), and transportation (Zidi et al., 2014). All such efforts involved the researchers making several proposals to develop new approaches or frameworks that would facilitate information access based on integrated knowledge representation, which ultimately leads to improved decision making.

\section{Proposed Approach}

Clearly, the review of related literature unveiled immense potential that could be unleashed from the integration of CBR and semantic web. Integrating the techniques of CBR and semantic web would provide several benefits, as indicated in previous studies, for the user in a number of ways. Existing efforts that focused on this integration have made great strides in many disciplines that, among others, include medical (Douali et al., 2014; Wang \& Tansel, 2013), information and communication technology (Syu et al., 2011; Preethi \& Devi, 2013), industrial management (Martin et al., 2013; Aarnio et al., 2014; Saïs \& Thomopoulos, 2014), and transportation (Bouhana et al., 2015).

Arguably, as highlighted in such studies, knowledge representation of a particular domain can be realized more effectively or efficiently based on the CBR technique that is supported by knowledge representation in the form of ontology of such domain. The realization of such representation will help improve the process of information access in terms of retrieval time and accuracy of information. Thus, in light of such capabilities, the process of decision making can be executed with greater efficacy.

\section{The Categories of Articles based on Digital Database Sources}

The categorisation of articles that had been filtered from the digital database sources is shown in Figure 3. Evidently, the search yielded different numbers of articles from the databases that met the selection criteria. First, Science Direct database contributed to the search process the highest number of articles, registering $61.9 \%(n=13)$ of the total selected $(N=21)$. Second, the IEEE Xplore database provided the second highest number of selected articles, contributing $23.8 \%(n=5)$ of the selected articles. Finally, in the third place, the search of articles on ACM database contributed only $14.3 \%$ (n $=3$ ) of the selected articles. In fact, preliminary search on ACM had identified another article, but it was later discarded from the set of selected articles as it had appeared in multiple databases. Clearly, as demonstrated above, articles that dealt with technical studies were mainly reported in Science Direct database, far exceeding other databases. In view of this revelation, this particular database can 
INTERNATIONAL JOURNAL OF ACADEMIC RESEARCH IN BUSINESS AND SOCIAL SCIENCES

Vol. 9, No. 14, Special Issue: Education 4.0: Future Learning. 2019, E-ISSN: 2222-6990 @ 2019 HRMARS

serve as the main source of information, in which technical articles discussing efforts in the integration of CBR and semantic techniques can be made available to researchers and scholars alike.

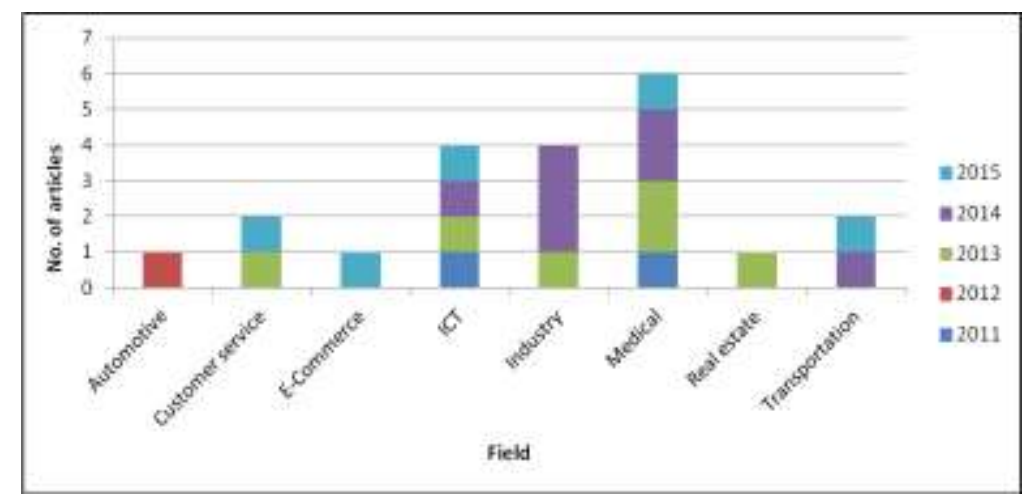

Figure 3. The number of articles from the digital databases based on the three categories of research focus.

\section{Visual Inspection}

Figure 4 illustrates the distribution of the 21 selected articles based on the three categories that had been published in the period from 2011 to 2015. Clearly, the year 2014 was the time in which many studies focussing on the integration of CBR and semantic web had been active, contributing $33.3 \%(n=7)$ of the selected articles. Of these articles, $23.8 \%(n=5)$ and $9.5 \%(n=2)$ of them were related to studies involving the proposals of working frameworks and new methods, respectively. Year 2013 saw the second highest number of selected articles, with $28.6 \%(n=6)$ of the selected articles deliberating both techniques. On closer examination, $14.3 \%(n=3)$ of the selected articles dealt with studies concentrating on system developments, and equally another $14.3 \%(n=3)$ dealt with the proposals of new methods. For year 2015, the number of articles dropped marginally to only 23.8\% ( $n=5)$ of the selected articles. Interestingly, this was the year in which efforts were directed toward the three categories of research, namely system development $(n=3)$, working framework ( $n$ $=1)$, and new method ( $n=1)$. The total number of selected articles dropped further in 2011 contributing only $9.5 \%(n=2)$ of the articles that involved the proposal of new methods. In 2012, there was only one selected article, which dealt with the proposal of frameworks, meagrely contributing $4.7 \%$ of the overall articles published in this period. The low numbers of articles published in the first two years of this period was hardly surprising as the research focus on the integration of the two techniques was in its infancy to attract the interest of the research fraternity. 


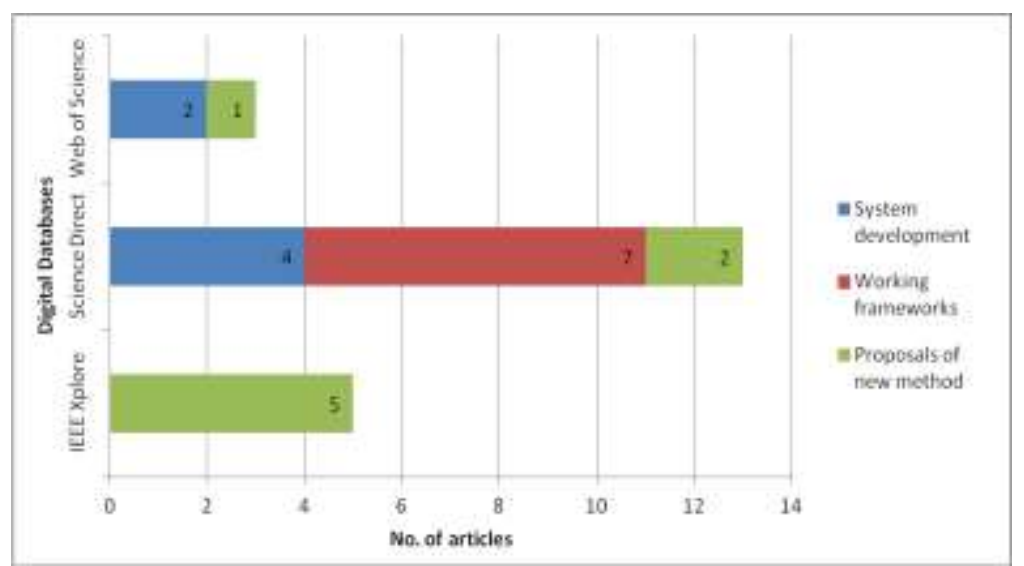

Figure 4. The number of articles based on the categories and years.

\section{Articles based on fields and years}

The applications based on the integration of the two techniques have featured in a number of fields, such as automotive industry, customer service, and medical, among others. Evidently, medical was the most prominent field, as attested by $28.6 \%(n=6)$ of the articles discussing the medical applications of such integration of techniques. Industry and ICT were the second most dominant areas that involved the applications of such integrated techniques, with $19 \%(n=4)$ of the articles discussing each area. The fields of customer service was less extensive, with only $9.5 \%(n=5)$ of the articles elaborating such application. Equally, only $9.5 \%(n=4)$ of the articles dealt with applications in the field of transportation. For automotive industry, e-commerce, and real estate, the applications of such technique were minimal, with only $4.8 \%(n=1)$ of the articles discussed each field. Figure 5 summarizes the number of selected articles based on the types of fields and publication years.

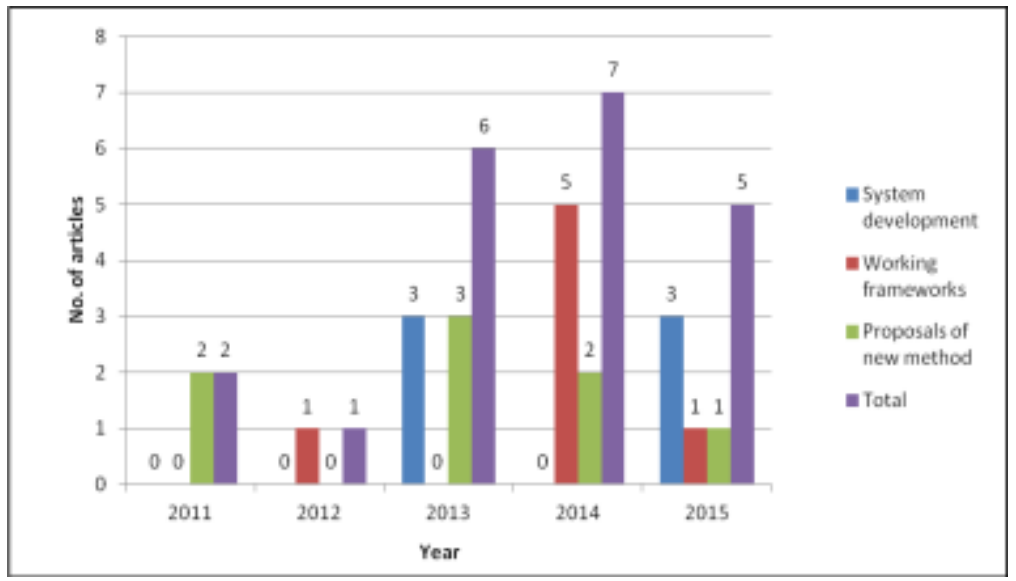

Figure 5. Number of articles based on fields and publication years. 
INTERNATIONAL JOURNAL OF ACADEMIC RESEARCH IN BUSINESS AND SOCIAL SCIENCES

Vol. 9, No. 14, Special Issue: Education 4.0: Future Learning. 2019, E-ISSN: 2222-6990 @ 2019 HRMARS

\section{Discussion}

The main focus of this article is to get an overview of the latest efforts conducted by researchers in the combination of cased-based reasoning technique and web semantics since 2011 until 2015. Through the analysis of the selected literature, a taxonomy has been produced.

\section{Motivation}

The analysis of the literature pertaining to the integration of CBR and semantic web revealed several benefits. More importantly, the main thrust of such integration is attributed to the knowledge representation of domain in the form of ontology. The benefits that can be reaped from the integration of both techniques include improved system development process through better utilization of energy and sources (Recio-García et al., 2014), fast and accurate information access (ElSappagh et al., 2015; Lee et al., 2015; Yuan et al., 2013; Douali et al., 2011; Chang et al., 2016; Pal \& Karakostas, 2014; Zidi et al., 2014; Preethi \& Devi, 2013; Martin et al., 2013; Saïs \& Thomopoulos, 2014; Bouhana et al., 2015), improved decision-making process (Sanchez et al., 2014), better implementation of information sharing (Flores et al., 2015; Douali et al., 2014), and improved maintenance process of domain knowledge representation (Lee et al., 2015; Douali et al., 2014; Aarnio et al., 2014). The above positive, promising findings of previous studies underscore the merits in integrating CBR and semantic web to make the process of information access faster and more precise and to help improve the process of decision making for every problem encountered.

\section{Recommendation}

Based on the analysis conducted on selected articles, a number of suggestions for improvement have been noted by the researchers. The main recommendation put forward by many researchers is involving scalibility. Knowledge is a key component in the integration of both of these techniques. Thus, ontology that represents the knowledge that will be used to implement the process of reasoning and decision-making (El-Sappagh et al., 2015; Lee et al., 2015; Sanchez et al., 2014; Douali et al., 2014; Wang \& Tansel, 2013; Martin et al., 2013; Bouhana et al., 2015) and a case base that holds all the solutions to past problems (Amailef \& Lu, 2013; Yuan et al., 2013; Preethi \& Devi, 2013) should be extend by adding new information, update and refined from time to time to ensure the capability of catering more complex problems. The addition and update of the ontology that involves various knowledge from relevant field allows the developed applications to be applied in other related domains (Pal \& Karakostas, 2014; Saïs \& Thomopoulos, 2014; Bouhana et al., 2015). In addition, the use of similarity calculation for the selection of a more appropriate and proper solution must be taken into account (Yuan et al., 2013; Aarnio et al., 2014).

In addition, most of the studies that were carried only focus on the retrieval of the CBR cycle. Improvement involving the process of cases adaptation is necessary to produce a more flexible system (El-Sappagh et al., 2015; Zidi et al., 2014; Martin et al., 2013; Bouhana et al., 2015). User interface is also an important component in producing an application that can be adopted and used by the users. Incorporating natural language query processing can improve and facilitate the ease of use of the applications (Bouhana et al., 2015). Finally, testing and evaluation process should be conducted to assess the viability of the integration of both techniques (Bouhana et al., 2015). 
INTERNATIONAL JOURNAL OF ACADEMIC RESEARCH IN BUSINESS AND SOCIAL SCIENCES

Vol. 9, No. 14, Special Issue: Education 4.0: Future Learning. 2019, E-ISSN: 2222-6990 @ 2019 HRMARS

\section{Limitation}

In this study, the analysis of the literature was limited to examining articles that were published from 2011 to 2015, which was a duration of only five years. Naturally, articles published in these recent five years would highlight the current research trend and development of systems based on the integration of CBR and semantic web. In addition, the article selected in this study only involves 4 main digital database. However, the selection of the database is believe that it would give a good and broad representation of the study because it is based on the main stream database which involves the study of scientific and technical in nature. Furthermore, the study also involved only articles written in english and do not reflect research that are written in other languages.

\section{Conclusion}

This study has revealed several important findings that show the current trend of research focusing on the integration of CBR and web semantic. Invariably, there are many articles that have been published, but their discussions mainly focus on either CBR or semantic web - not on the integration of the two techniques. As found in the critical review of related literature, involving hundreds of articles, only 21 articles have thus far been published that elaborate such integration of the two techniques.

In pursuing this research, the researchers were able to develop a taxonomy of the integration of both techniques to help classify studies into three main strands, namely system development, working framework, and new method of implementation, more systematically.

In addition, this study also helped highlight the strengths and advantages of the integration of CBR and semantic web in diverse fields, especially in the medical field. This is not suspiring given the nature of medical problems - which have serious impacts on patients' wellbeing - necessitating accurate and fast solutions. Of course, other less critical fields, such as automotive industry, e-commerce, and real estate, have also made use of applications based on such integration to some degree of success.

Overall, this particular finding suggests that more efforts are required to address the imperative of developing greater understanding on the integration of both techniques. With improved knowledge, developers can eventually build effective applications to deal with a wide range of problems in today's challenging world. From the findings it is revealed that there has been no research conducted in the field of education in applying the integration of the two techniques which is the main interest of the author. Therefore, it is recommended that studies in applying the integration of both CBR and web semantic techniques should be carried out in the education domain to enhance teaching and learning methods in a more effective and efficient way.

\section{References}

Ahmed, U., Khalid, N., Ammar, A., \& Shah, M. H. (2017). Assessing moderation of employee engagement on the relationship between work discretion, job clarity and business performance in the banking sector of Pakistan. Asian Economic and Financial Review, 7(12), 1197-121. https://doi.org/10.18488/journal.aefr.2017.712.1197.1210 
INTERNATIONAL JOURNAL OF ACADEMIC RESEARCH IN BUSINESS AND SOCIAL SCIENCES

Vol. 9, No. 14, Special Issue: Education 4.0: Future Learning. 2019, E-ISSN: 2222-6990 @ 2019 HRMARS

Ahmed, U., Majid, A. H. A., \& Zin, M. M. (2016). Moderation of meaningful work on the relationship of supervisor support and coworker support with work engagement. The Journal of Business, Economics, and Environmental Studies (JBEES), 6(3), 15-20.

Aamodt, A., \& Plaza, E. (1994). Case-based reasoning: Foundational issues, methodological variations, and system approaches. Al communications, 7(1), 39-59.

Aarnio, P., Seilonen, I., \& Friman, M. (2014, September). Semantic repository for case-based reasoning in CBM services. In Proceedings of the 2014 IEEE Emerging Technology and Factory Automation (ETFA) (pp. 1-8). IEEE.

Amailef, K., \& Lu, J. (2013). Ontology-supported case-based reasoning approach for intelligent mGovernment emergency response services. Decision Support Systems, 55(1), 79-97.

Bergmann, R., Kolodner, J., \& Plaza, E. (2005). Representation in case-based reasoning. The Knowledge Engineering Review, 20(03), 209-213.

Berners-Lee, T., Hendler, J., \& Lassila, O. (2001). The semantic web. Scientific American, 284(5), 2837.

Bouhana, A., Zidi, A., Fekih, A., Chabchoub, H., \& Abed, M. (2015). An ontology-based CBR approach for personalized itinerary search systems for sustainable urban freight transport. Expert Systems with Applications, 42(7), 3724-3741.

Chang, J. W., Lee, M. C., \& Wang, T. I. (2016). Integrating a semantic-based retrieval agent into casebased reasoning systems: A case study of an online bookstore. Computers in Industry, 78, 29-42.

d'Aquin, M., Lieber, J., \& Napoli, A. (2013). Decentralized case-based reasoning and Semantic Web technologies applied to decision support in oncology. The Knowledge Engineering Review, 28(04), 425-449.

Douali, N., Csaba, H., De Roo, J., Papageorgiou, E. I., \& Jaulent, M. C. (2014). Diagnosis support system based on clinical guidelines: comparison between case-based fuzzy cognitive maps and Bayesian networks. Computer methods and programs in biomedicine, 113(1), 133-143.

Douali, N., De Roo, J., Papageorgiou, E. I., \& Jaulent, M. C. (2011, June). Case-Based Fuzzy Cognitive Maps (CBFCM): new method for medical reasoning: comparison study between CBFCM/FCM. In Fuzzy Systems (FUZZ), 2011 IEEE International Conference (pp. 844-850). IEEE.

El-Sappagh, S., Elmogy, M., \& Riad, A. M. (2015). A fuzzy-ontology-oriented case-based reasoning framework for semantic diabetes diagnosis. Artificial intelligence in medicine, 65(3), 179-208.

Flores, R. L., Belaud, J. P., Negny, S., \& Le Lann, J. M. (2015). Open computer aided innovation to promote innovation in process engineering. Chemical Engineering Research and Design, 103, 90107.

Kolodner, J. (2014). Case-based reasoning. Morgan Kaufmann.

Lee, C. H., Wang, Y. H., \& Trappey, A. J. (2015). Ontology-based reasoning for the intelligent handling of customer complaints. Computers \& Industrial Engineering, 84, 144-155.

Martin, A., Emmenegger, S., \& Wilke, G. (2013, November). Integrating an enterprise architecture ontology in a case-based reasoning approach for project knowledge. In Enterprise Systems Conference (ES), 2013 (pp. 1-12). IEEE.

Minhas, S., Juzek, C., \& Berger, U. (2012). Ontology based Intelligent assistance system to support manufacturing activities in a distributed manufacturing environment. Procedia CIRP, 3, 215-220.

Pal, K., \& Karakostas, B. (2014). A multi agent-based service framework for supply chain management. Procedia Computer Science, 32, 53-60. 
INTERNATIONAL JOURNAL OF ACADEMIC RESEARCH IN BUSINESS AND SOCIAL SCIENCES

Vol. 9, No. 14, Special Issue: Education 4.0: Future Learning. 2019, E-ISSN: 2222-6990 @ 2019 HRMARS

Preethi, N., \& Devi, T. (2013, January). New Integrated Case And Relation Based (CARE) Page Rank Algorithm. In Computer Communication and Informatics (ICCCI), 2013 International Conference (pp. 1-8). IEEE.

Recio-García, J. A., González-Calero, P. A., \& Díaz-Agudo, B. (2014). Template-based design in colibri studio. Information Systems, 40, 168-178.

Saïs, F., \& Thomopoulos, R. (2014). Ontology-aware prediction from rules: A reconciliation-based approach. Knowledge-Based Systems, 67, 117-130.

Sanchez, E., Peng, W., Toro, C., Sanin, C., Graña, M., Szczerbicki, E., ... \& Brualla, L. (2014). Decisional DNA for modeling and reuse of experiential clinical assessments in breast cancer diagnosis and treatment. Neurocomputing, 146, 308-318.

Syu, Y., Fanjiang, Y. Y., Kuo, J. Y., \& Ma, S. P. (2011, July). An automated workflow composition to semantic web services. In Machine Learning and Cybernetics (ICMLC), 2011 International Conference on (Vol. 2, pp. 903-907). IEEE.

Wang, H. T., \& Tansel, A. U. (2013). MedCase: a template medical case store for case-based reasoning in medical decision support. In Proceedings of the 2013 IEEE/ACM International Conference on Advances in Social Networks Analysis and Mining (pp. 962-967). ACM.

Yuan, X., Lee, J. H., Kim, S. J., \& Kim, Y. H. (2013). Toward a user-oriented recommendation system for real estate websites. Information Systems, 38(2), 231-243.

Zidi, A., Bouhana, A., Abed, M., \& Fekih, A. (2014). An ontology-based personalized retrieval model using case base reasoning. Procedia Computer Science, 35, 213-222. 